\title{
Sociologia do Corpo é Sociologia da Educação Física
}

Rafael da Silva Mattos*

\begin{abstract}
Resumo: O texto é uma resenha do livro de Duret e Roussel intitulado Le corps et ses sociologies. O livro apresenta uma discussão sociológica da corporeidade a partir de vários autores clássicos. As interações sociais corporais como os olhares, fisionomias, posturas, gestos são construções culturais e históricas. $\mathrm{O}$ corpo se revela com produto da sociedade, mas também como construtor de sentidos e significados culturais. Os autores elaboram uma discussão do corpo em sete capítulos, apresentando inúmeros problemas de estudo: os usos sociais do corpo; as marcas corporais na sociedade; os gestos corporais como regulares de interações sociais; o corpo e a fenomenologia; o corpo e a modernidade; o corpo e as normas de beleza; o corpo e as identidades sexuais; o corpo e as relações de poder.

Palavras-chave: Imagem corporal. Educação Física. Valores sociais.
\end{abstract}

Qual o papel do corpo em nossa sociedade? Mais ainda, qual o papel do corpo, como objeto de estudo, na Educação Física? Será o corpo descrito como o meio privilegiado de interiorização das estruturas sociais? Ou como ferramenta de interação? Ou como fonte de apropriação do mundo sensível? Sem dúvida, não faltam pensadores que se debruçaram direta ou indiretamente sobre a corporeidade. Platão, Descartes, Espinosa, Nietzsche, MerleauPonty, Foucault, Deleuze, Butler são alguns filósofos que tematizaram o corpo. Nas ciências sociais, toda uma geração pode ser considerada: Durkheim, Mauss, Bourdieu, Boltanski, Wacquant, LéviStrauss, Gabriel Tarde, Simmel, Margaret Mead, Mary Douglas,

*Licenciado em Educação Física e Desportos. Graduando em Filosofia.Doutorando em Saúde Coletiva (UERJ). Membro do Grupo de Pesquisa CNPq Racionalidades Médicas e Práticas de Saúde e do Laboratório do Imaginário Social sobre Atividades Corporais e Lúdicas (UERJ). Rio de Janeiro, RJ, Brasil. E-mail: profmattos2010@gmail.com 
Evans-Pritchard, Goffman, Becker, Victor Turner, Norbert Elias, Csordas, entre tantos outros.

Uma das marcas da individualidade moderna e pós-moderna, evidentemente, correlaciona-se com as mudanças corporais que sinalizam a construção pessoal. O corpo é o primeiro ponto de ancoragem ao qual o indivíduo se constrói. Não é sem razão que a primeira etapa no desenvolvimento psicogenético do sujeito foi descrita por Piaget $(1963,2000)$ como "período sensório-motor". A existência começa pelo corpo. Foi com essa percepção que Le Breton (1992) iniciou sua obra La Sociologia du Corps. No corpo e através do corpo começa nossa história. Por suas possibilidades de transformação, o corpo, ao longo da vida, permite a existência de identidades flexíveis.

No livro "Le corps et ses sociologies", Pascal Duret e Peggy Roussel nos apresentam uma discussão profunda de inúmeras posições sociológicas sobre o corpo. O livro não foi elaborado para profissionais de Educação Física, mas seu conteúdo é fundamental para todos aqueles que participam direta e indiretamente da construção teórica e prática de uma Educação Física a partir das Humanidades. Pensar a Educação Física, seja como área de conhecimento ou como prática pedagógica, exclusivamente pelos fundamentos biológicos e biomecânicos é reduzir a dimensão desse saber-fazer tão em evidência no mundo contemporâneo. É com muita satisfação que nós profissionais de Educação Física incorporamos em nossos currículos de graduação e pós-graduação, leituras clássicas da Sociologia, Antropologia, Filosofia, Psicologia, Psicanálise, História e Pedagogia. Todos esses campos de conhecimento em algum momento pensaram a corporeidade. Duret e Roussel nos brindam com uma leitura obrigatória do corpo pela abordagem sociológica. Wacquant (2002a, 2002b) afirma que se podemos obter conhecimentos do universo social por meio de nossos corpos, nossa tarefa não é fazer apenas Sociologia do Corpo, mas também Sociologia a partir do corpo, considerando-o como organismo socializado e sensório de construção social.

Movimento, Porto Alegre, v. 16, n. 04, p. 293-304, outubro/dezembro de 2010. 
No capítulo I, a ênfase de Duret e Roussel está na relação entre corpo e estrutura social, típica discussão da escola sociológica francesa. No capítulo II, a discussão estende-se para a relação entre os gestos corporais e a interação social, destacando o interacionismo simbólico. No capítulo III, a discussão é sobre o corpo sensível e expressivo que será retomada no capítulo $\mathrm{V}$ com as temáticas da estética e da ética. No capítulo IV, os autores tratam da relação entre o corpo e Modernidade. Finalizando o livro, o capítulo VI trata da construção das identidades sexuais e gêneros e o capítulo VII das relações de poder e saber que se materializam no corpo.

Duret e Roussel afirmam que o corpo não foi esquecido pela sociologia. Émile Durkheim (2007) em seu livro "A Divisão do Trabalho Social" fez do corpo um elemento indispensável da vida social. No livro "As Formas Elementares da Vida Religiosa", Durkheim (2008) descreve o corpo no centro da experiência de interdição entre sagrado e profano, bem como da socialização pela presença dos fiéis. Com Pierre Bourdieu $(1977,1984)$ veremos o corpo como veículo do "habitus". Como meio de uma transmissão freqüentemente inconsciente de dispositivos sociais e de gostos alimentares, estéticos, esportivos, sexuais. Para Bourdieu, o corpo exerce ao mesmo tempo uma tripla função: memória, aprendizagem dos hábitos de classe e marcador de posição social. O corpo é, então, uma memória ativa, um lugar de inscrição da coletividade, produzindo acordos entre os agentes e as práticas fora dos cálculos estratégicos e das referências conscientes. O corpo está no centro da experiência da classe como mecanismo ao mesmo tempo de interiorização (incorporação de valores) e de exteriorização das disposições adquiridas.

Duret e Roussel também retomam Luc Boltanski (1971), autor que desenvolve estudos sobre o corpo tomando a classe social como elemento de análise. Ele produz uma sociologia da puericultura e dos cuidados maternos, compreendendo as diferenciações nos discursos médicos à destinação das mães de diferentes grupos sociais. Da mesma forma, Boltanski discute as diferentes práticas de embelezamento, de alimentação, de uso de álcool, de atitudes

Movimento, Porto Alegre, v. 16, n. 04, p. 293-304, outubro/dezembro de 2010. 
médicas preventivas, de regimes emagrecedores, de esportes conforme classes sociais.

Ao longo do texto, Duret e Roussel procuram nos mostrar como alguns gestos podem substituir com precisão uma mensagem oral: "não"

a) virar a cabeça da esquerda para a direita significa dizer

b) colocar o indicador perto da cabeça com um movimento de rotação quando você quer dizer que alguém está louco

c) mudanças de posições da cabeça e das mãos são corriqueiras nas interações sociais

d) piscar os olhos quando se está flertando com alguém ou querendo enganar o outro

Durante as trocas, independentemente das intenções, uns se aproximam para assinalar seu interesse, outros recuam para se afastar da aproximação excessiva de um corpo. Cada um aplica suas próprias categorias de julgamento no estabelecimento das distâncias intencionais nas relações interpessoais. Para Duret e Roussel, as trocas se organizam como uma "dança", na qual as microgestualidades se misturam. Durante as conversas, existem microgestualidades que estão ocorrendo a todo o momento e permitem a interação entre os agentes sociais. A vez de cada um falar é percebida pelos outros através de gestos corporais sutis. O corpo, sistema de comunicação, funciona como uma linguagem.

Ao retomar a construção do corpo na Modernidade, Duret e Roussel afirmam que o corpo inaugura uma nova relação com a esfera privada na qual o hedonismo e a busca do prazer se tornam legítimos. Para os autores, o corpo triunfa sobre um modo individualizado, íntimo e despolitizado.

Os autores retomam Gilles Lipovetsky (2005) para descrever um estado de narcisismo avançado. Em "AEra do Vazio", Lipovetsky mostra como na sociedade ocidental pós-moderna, o lugar deixado vazio pelo fim da transcendência e pela agonia da fala política veio a ser ocupado pelo narcisismo. Em uma sociedade, na qual o sentimento

Movimento, Porto Alegre, v. 16, n. 04, p. 293-304, outubro/dezembro de 2010. 
de coletividade não fornece mais modelos decisivos, o culto ao corpo torna-se um fim em si mesmo. A aparência recobre a totalidade de si fornecendo uma espécie de bioidentidade ao indivíduo (ANDRIEU, 1995, 2002, 2008, 2010). O corpo permite uma existência puramente atual, sem transcendência, sem outro objetivo que não seja seu potencial físico e seu potencial de sedução. A atenção dada ao corpo é a princípio uma luta contra seu envelhecimento, um combate permanente contra os signos de sua degradação e um esforço para se colocar fora do tempo.

A paixão do corpo jovem torna-se o pilar do processo de personalização. O mito da eterna juventude é levado pela busca de um corpo sem idades. Nenhuma parte do corpo deve escapar dessa vigilância. Do ponto de vista da evolução das academias de ginástica, há um incessante aumento das variedades das práticas ofertadas: jump, gap, acqua training, body combat, body attack, ball training, bioginástica, body boxe, body balance, core training, dance mix, fit flex, fit ball, flex e relax, hidro-jump, hidroginástica, ginástica localizada, spinning, running class, hidro-power, hidro-relax, jumpow, power pool, power spin, step, entre outras atividades. As academias se transformaram em centros de modelação do corpo. Tudo é oferecido. $\mathrm{O}$ "personal training" é um programa individualizado que cada praticante escolhe, no conjunto das atividades disponíveis, aquelas que são mais convenientes na sua autoconstrução.

O cliente constrói seu programa individualizado e seleciona algumas atividades: alongamentos, musculação, ginástica, treinamento cardiovascular, danças, esportes de combate. $\mathrm{O}$ maior dos defeitos não é mais o sedentarismo, mas a incapacidade de individualizar o cuidado com o corpo. Como veicula a propaganda, destacada por Duret e Roussel: "ir a uma academia de ginástica é encontrar-se consigo mesmo". O corpo toma importância crescente nas formas de sedução pela imagem.

Nas relações sociais cotidianas, Dortier (2008) afirma que as pessoas mais belas fisicamente atraem mais simpatia por parte de seus colegas. Busca-se com prazer sua companhia, ao passo que há um afastamento dos obesos, feios e deficientes. A beleza oferece

Movimento, Porto Alegre, v. 16, n. 04, p. 293-304, outubro/dezembro de 2010. 
um precioso capital de sedução. Esse capital é um fator de desigualdade muito forte nas relações humanas em geral e nas relações amorosas, em particular. Na escola, no trabalho, na amizade constata-se que é mais vantajoso socialmente ser bonito. Isso conta de maneira significativa no julgamento que os outros fazem sobre nós. Apesar do "amorosamente correto" que nos induz a amar alguém, a princípio, por sua personalidade, sua generosidade, sua inteligência, seu humor, seu caráter, a beleza no mundo contemporâneo se tornou forte fator de atração e identidade entre os seres.

Os autores retomam David Le Breton (2000, 2002a, 2002b) que sugere a existência de um detalhamento entre si e seu corpo. $\mathrm{O}$ corpo é o outro mais próximo, é o duplo fiel, o amigo verdadeiro, o confidente. A Modernidade sacraliza o corpo em uma realidade autônoma sobre o olhar atento de seu proprietário. O corpo deve se tornar um templo que ofereça vantagem àquele que o habita. Nesse sentido, a paixão crescente pelo cuidado corporal é uma consequiência da estruturação individualista da sociedade moderna. A individualização na sua fase atual contribui para a atribuição ao corpo de um valor de parceiro privilegiado.

O indivíduo busca nele mesmo o que a sociedade não pode mais oferecer. Isolado pelo declínio de valores coletivos e freqüentemente diante da solidão, o ator social pode mesmo recriar uma sociabilidade imaginária em um espaço de diálogo entre si e seu corpo, demandando cuidados excessivos sobre o corpo. Assim, o indivíduo se isolando não se ocupa mais do que explorar e entreter seu corpo para encontrar nele mesmo o parceiro que falta nos seus laços sociais.

Já no final do livro, no Capítulo VI, os autores procuram retomar a discussão sociológica entre o corpo e a construção de gênero. Como o corpo atua na construção da identidade de gênero? Se tornar homem ou mulher não pode ser encarado unicamente sob ângulo da diferenciação biológica, mas necessita ser compreendido a partir da construção social do gênero. O "masculino" assim como o "feminino" são construções sociais. Podemos acrescentar de um ponto de vista antropológico mais radical que as próprias diferenças biológicas são

Movimento, Porto Alegre, v. 16, n. 04, p. 293-304, outubro/dezembro de 2010. 
produzidas historicamente na cultura. Autores clássicos nessa discussão teórico-conceitual como Michel Bozon (2002) Michel Pollak (1986, 1990) também são citados por Duret e Roussel.

Longe de naturalizar os sexos, Duret e Roussel afirmam que os pesquisadores, em particular, os americanos e canadenses, mais do que os franceses, se interessaram pela questão e aprenderam a diferenciar a identidade sexual (masculino ou feminino) e a identidade de gênero (representações de si através das categorias de ações definidas como o que é próprio dos homens e das mulheres). Nesse sentido, a discussão socioantropológica sobre gênero é cada vez mais pertinente, pois reconhecemos que vivemos historicamente em uma cultura masculina de afirmação da força, do desempenho e da competição. Nessa cultura, o homem por ter o papel social de ativo, não exprime, na vida pública, características consideradas femininas, procurando sempre reafirmar sua virilidade. Trata-se do que Bourdieu (1998) chama de visão androcêntrica de mundo.

Os autores mostram que mesmo que não haja consenso sobre a apreciação da virilidade, os atributos físicos que a caracterizam são muito homogêneos. Em uma pesquisa realizada com 1511 jovens de idades entre 17 e 23 anos ( 750 moças e 761 rapazes) que deveriam citar três atributos físicos da virilidade, $98 \%$ dos meninos, citaram o músculo, a massa e a força como sinais evidentes de virilidade, ao passo que quase $70 \%$ das mulheres reafirmam o mesmo. Trata-se da dominação masculina tão cara a Bourdieu (1998). Para o autor, as próprias mulheres podem expressar formas de agir e pensar que são produtos sociais da representação masculina de superioridade. Nesse sentido, seus atos de conhecimento são, inevitavelmente, atos de reconhecimento, de submissão. Há uma imposição simbólica aos dominados.

No entanto, Duret e Roussel ressaltam que as meninas conseguem destacar a virilidade dos critérios corporais mais facilmente do que os rapazes. Para elas, trata-se primeiramente de uma questão de caráter. Para os meninos, ao contrário, não se pode ser viril sem ter um corpo que se faça respeitar. As imagens do corpo viril são principalmente diferenciadas conforme grupos sociais.

Movimento, Porto Alegre, v. 16, n. 04, p. 293-304, outubro/dezembro de 2010. 
Para os jovens de origem popular, o músculo buscado é um músculo útil que se opõe ao cultivo da simples aparência. Sem sistematicamente abandonar os estereótipos do corpo viril, os jovens de classes mais favorecidas encontram outras formas de expressar sua virilidade do que aquela do afrontamento físico privilegiado nos meios populares.

Por fim, no último capítulo, os autores retomam Michel Foucault (1993) para discutir os modos de controle social sobre o corpo. A materialidade do poder se exerce sobre o corpo dos indivíduos. $\mathrm{O}$ domínio e o controle das paixões corporais foram adquiridos pelo efeito do investimento do poder: a ginástica, os exercícios, o desenvolvimento muscular, a nudez, a exaltação do belo corpo. Tudo isso produz o desejo de aperfeiçoar o próprio corpo através de trabalho insistente, obstinado, meticuloso. O poder penetrou no corpo e pode investir de distintas maneiras. Da microfísica a biopolítica, o corpo é o local onde se manifestam os efeitos do poder. Nada é mais material, mais físico, mais corporal que o exercício do poder. Surveiller et Punir é uma tentativa de mostrar como um novo modo de pensar se instaurou a partir das relações de poder e saber sobre o corpo, diz Foucault (1994). Diante disso, Duret e Roussel estendem a discussão para a gestão da sexualidade, a epidemia da AIDS, a clonagem e o transplante de órgãos.

O que mais ganhamos com o livro "Le corps et ses sociologies" é uma possibilidade de ampliar nossa discussão para os modelos de corpo na contemporaneidade, os significados culturais das práticas corporais, a simbologia do corpo na cultura, as estratégias, contrapoderes, resistências e táticas elaboradas pelos sujeitos em torno dos modelos de corpo.

Nesse sentido, Duret e Roussel constroem uma bela obra que nos ajuda a ampliar nossa discussão sobre a corporeidade nas ciências humanas e sociais. De Marcel Mauss com as "Técnicas Corporais" a Émile Durkheim, compreenderemos que a sociedade constrói o corpo. A cultura se inscreve no corpo e as diferenças corporais são produtos das diferenças sociais. Cada ser envolvido em exercícios físicos, da escola às academias de ginástica, produz e reproduz uma

Movimento, Porto Alegre, v. 16, n. 04, p. 293-304, outubro/dezembro de 2010. 
realidade coletiva, inscrita e rabiscada nos ossos, músculos e pele. O sistema simbólico condiciona as ações corporais dos sujeitos de forma inconsciente. Cabe a nós compreender esse sistema.

Mas se o leitor achar que o livro é estruturalista ou determinista se engana. O dilema sociológico se coloca e os autores oscilam entre duas tendências: é a ação que produz a estrutura ou a estrutura que condiciona as ações? Nós internalizamos as estruturas sociais e as reproduzimos nas relações sociais sem percebemos conscientemente. Mas há ação? Há agenciamento? Há resistências? Sim, os autores deixam subentendido. As interações sociais corporais: o olhar, as fisionomias, as posturas podem ser construídas pelos atores. O corpo não é apenas produto da sociedade, mas também construtor da sociedade. No corpo, há síntese entre ação e estrutura. São as práticas corporais que produzem e reproduzem simultaneamente a sociedade. Se quisermos pensar uma Educação Física como educação, precisamos pensar a razão de ser da educação, isto é, a cultura. Falar em corpo e sociologia, como fazem Duret e Roussel, é falar em cultura corporal.

Movimento, Porto Alegre, v. 16, n. 04, p. 293-304, outubro/dezembro de 2010. 
Body' sociology is the sociology of Physical

\section{Education}

Abstract: The text is a book review of Duret Roussel entitled Le corps et ses sociologies. The book presents a sociological discussion of the way in which the human brain recognizes and uses the body as means of interaction, from various classic authors. Bodily social interactions such as looks, facial expressions, posture, gestures are cultural and historical constructs. The body is not only revealed as a product of society but also as constructor of cultural meanings. The authors have elaborated a discussion on the body, in seven chapters, presenting innumerous problems of study as the social uses of the body; the body marks in society; body gestures seen as a regular in social interactions; the body and phenomenology; body and modernity; body and the standards of beauty; the body and sexual identities; the body and the power relations. Keywords: Body Image. Physical Education. Corporality. Social values.

Sociología del cuerpo es la sociología de la
Educación Física
Resumen: El texto es una reseña del libro de Duret y
Roussel titulado Le corps et ses sociologies. El mismo
presenta un debate sociológico sobre la corporeidad
desde el punto de vista de varios autores clásicos.
Las interacciones sociales corporales como las
miradas, las fisionomías, las posturas, los gestos, son
construcciones sociales e históricas. El cuerpo se
revela como producto de la sociedad, pero también
como constructor de sentidos y significados culturales.
Los autores establecen un debate sobre el cuerpo en
siete capítulos, y presentan innumerables problemas
de estudio: los usos sociales del cuerpo, las marcas
corporales en la sociedad, los gestos corporales como
reguladores de la interacción social, el cuerpo y la
fenomenología, el cuerpo y la modernidad, el cuerpo y
los estereotipos de belleza, el cuerpo y las identidades
sexuales, el cuerpo y las relaciones de poder.
Palabras Clave: Imagen corporal. Educación Física.
Valores sociales.

Movimento, Porto Alegre, v. 16, n. 04, p. 293-304, outubro/dezembro de 2010. 


\section{REFERÊNCIAS}

ANDRIEU, B. Les cultes du corps. Paris: L'Harmattan, 1995. (Collection: Santé, sociétés et cultures).

La Nouvelle Philosophie du corps. Paris: Erès, 2002.

Mutations Sensorielles. Paris: Mort Qui Trompe, 2008.

Textes clés de philosophie du corps. Paris: Vrin, 2010.

BOLTANSKI, Les usages sociaux du corps, Annales E.S.C, n. 26, v. 1, p. 205-233, 1971.

BOURDIEU, P. Méditations pascaliennes. Paris: Éditions du Seuil, 1977.

Questions de sociologie. Paris: Ed. de Minuit, 1984.

La domination masculine. Paris: Éditions de Seuil, 1998.

BOZON, M. Sociologie de la Sexualité. Paris: Nathan, 2002. (Collection Sociologie, 128).

DORTIER, J-F. La tyrannie de la beauté. Sciences Humaines, n. 195, jul. 2008. (Le corps sous controle),

DURKHEIM, E. De la division du travail social. Paris: PUF, 2007. 2008. Les formes élementaires de la vie religieuse. 6 ed. Paris: PUF,

FOUCAULT, M. Surveiller et punir. Paris : Éditions Gallimard, 1993.

. Dits et Écrits. Paris: Gallimard, 1994.

LE BRETON, D. Adieu au corps. Paris: Le Métaillié, 2000.

Antropología del Cuerpo y Modernidad. Buenos Aires: Nueva Vision, 2002a. (Cultura y Sociedad).

Signes d'Identité: tatouages, piercings et autres marques corporelles, Paris: Métailié, 2002b.

La Sociologie du Corps. Paris: PUF, 1992.

LIPOVETSKY, G. A Era do Vazio: ensaio sobre o individualismo contemporâneo. Barueri: Manole, 2005.

PIAGET, J. Le jugement moral chez l'enfant. Paris : PUF, 2000.

Movimento, Porto Alegre, v. 16, n. 04, p. 293-304, outubro/dezembro de 2010. 


\section{Resenha}

La naissance de l'intelligence chez l'enfant. Paris : Delachaux et Niestlé, 1963.

POLLAK, M. A homossexualidade masculina, ou: a felicidade no gueto? In: ARIÈS, $\mathrm{P}$ e BENIN, A. (Orgs.) Sexualidades Ocidentais: contribuições para a história e para a sociologia da sexualidade. São Paulo: Brasiliense, 1986.

Os Homossexuais e a AIDS: sociologia de uma epidemia. São Paulo: Estação Liberdade, 1990.

WACQUANT, L.J.D. Corps et ame: carnets ethnographiques d'um aprrenti boxeur. Paris: Agone, 2002a.

WACQUANT, L.J.D. O Legado Sociológico de Pierre Bourdieu: duas dimensões e uma nota pessoal. Revista de Sociologia Política, Curitiba, v. 19, p. 95-110, nov. 2002b.

Movimento, Porto Alegre, v. 16, n. 04, p. 293-304, outubro/dezembro de 2010. 